\title{
Catalytic Pulping of Wood
}

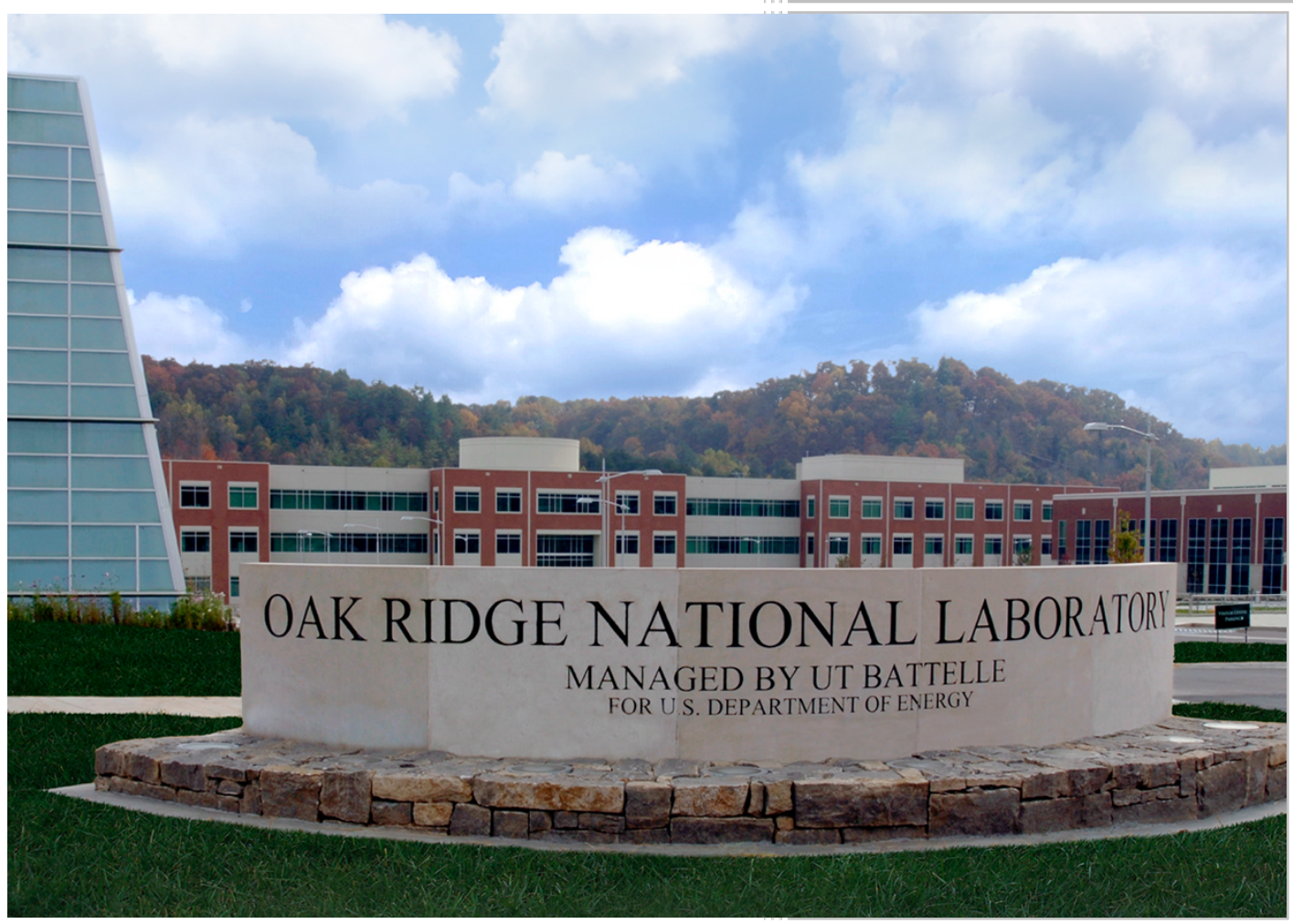

Approved For Public Release. Distribution is unlimited.

CRADA Final Report NFE-16-06406
Jerry M. Parks

June 3, 2019 


\section{DOCUMENT AVAILABILITY}

Reports produced after January 1, 1996, are generally available free via US Department of Energy (DOE) SciTech Connect.

Website http://www.osti.gov/scitech/

Reports produced before January 1, 1996, may be purchased by members of the public from the following source:

National Technical Information Service

5285 Port Royal Road

Springfield, VA 22161

Telephone 703-605-6000 (1-800-553-6847)

TDD 703-487-4639

Fax 703-605-6900

E-mailinfo@ntis.gov

Website http://www.ntis.gov/help/ordermethods.aspx

Reports are available to DOE employees, DOE contractors, Energy Technology Data Exchange representatives, and International Nuclear Information System representatives from the following source:

Office of Scientific and Technical Information

PO Box 62

Oak Ridge, TN 37831

Telephone 865-576-8401

Fax 865-576-5728

E-mail reports@osti.gov

Website http://www.osti.gov/contact.html

This report was prepared as an account of work sponsored by an agency of the United States Government. Neither the United States Government nor any agency thereof, nor any of their employees, makes any warranty, express or implied, or assumes any legal liability or responsibility for the accuracy, completeness, or usefulness of any information, apparatus, product, or process disclosed, or represents that its use would not infringe privately owned rights. Reference herein to any specific commercial product, process, or service by trade name, trademark, manufacturer, or otherwise, does not necessarily constitute or imply its endorsement, recommendation, or favoring by the United States Government or any agency thereof. The views and opinions of authors expressed herein do not necessarily state or reflect those of the United States Government or any agency thereof. 
Biosciences Division

\title{
Catalytic Pulping of Wood
}

Jerry M. Parks (ORNL)

and

David B. Turpin (APPTI)

Date Published:

June 3, 2019

\author{
Prepared by \\ OAK RIDGE NATIONAL LABORATORY \\ Oak Ridge, Tennessee 37831-6283 \\ managed by \\ UT-BATTELLE, LLC \\ for the \\ US DEPARTMENT OF ENERGY \\ under contract DE-AC05-00OR22725
}

Approved for public release 


\begin{abstract}
The pulp and paper industry is an essential segment of the U.S. economy, making products necessary for everyday life from renewable resources. Lignin is a naturally occurring polymer in wood that must be removed to expose the polysaccharides used in the pulping industry to produce paper products. Kraft pulping, the predominant technology, is capital- and energy-intensive, and it provides a less efficient use of wood resources than desired. Catalytic methods offer a viable alternative to increase cellulose fiber yield by improving selectivity, reducing energy use and eliminating the formation of odor-causing mercaptans associated with kraft pulping. If successful, catalytic methods will improve yield, reduce fiber waste, reduce energy use, lower the cost of bleaching and decrease the cost of air emission controls. The purpose of this CRADA was to combine industrial expertise in wood pulping with national laboratory expertise in high-performance computing eventually leading to the design of new catalysts that can remove lignin from wood pulp efficiently and cost-effectively. A combined computational and experimental approach was used to investigate the detailed chemical mechanism of oxidation of ligninlike small molecules by a cobalt-based catalyst. These reactions were also investigated in the laboratory by synthesizing the catalyst and lignin-like phenols and measuring reaction yields for the formation of benzoquinones and benzaldehydes. In this report we summarize the accomplishments of the project.
\end{abstract}

\title{
Statement of Objectives
}

The Alliance for Pulp and Paper Technology Innovation (APPTI), formerly Agenda 2020, is an industryled consortium that promotes the development of advanced manufacturing technologies for the pulp and paper industry. Among the main objectives of APPTI are to identify high-priority technology challenges for the pulp and paper industry and to promote pre-competitive scientific R\&D projects to address those challenges. The goals of the organization are to reduce water consumption and enhance water reuse, reduce energy use and carbon emissions, increase manufacturing process efficiency, improve raw material yield, and develop new bio-based products.

The purpose of chemical pulping is to remove lignin from cellulosic biomass while preserving polysaccharides required for pulp strength. Kraft pulp is manufactured with a caustic mixture of alkaline chemicals that hydrolyze lignin from the desired carbohydrates. Kraft pulping is capital-intensive, and provides a lower yield than desired because it degrades $\sim 30 \%$ of non-cellulosic polysaccharides. Improved pulping technologies are therefore of high interest across the pulp and paper industry.

Chemical catalysts can accelerate delignification, and they show promise as a new technology that can achieve better selectivity and fiber yield at equal or lower cost than conventional methods. Cobalt-based oxidative catalysts are attractive leads because they (i) operate under mild conditions, (ii) use plentiful $\mathrm{O}_{2}$ and non-precious transition metals, and (iii) produce valuable chemical feedstocks as byproducts.

Key drivers of catalytic efficiency are largely unknown. Experimental efforts to develop improved cobalt catalysts have yielded only minor increases in reactivity or stability. Structure-property relationships have yielded a few clues to the features that govern catalytic efficiency. For example, the steric and electronic properties of axial unsaturated nitrogen heterocycles correlate moderately with the oxidation of monolignols. Mechanisms of oxidative delignification by cobalt salen have been proposed based on sparse spectroscopic and kinetic data, but no definitive, detailed mechanisms have been reported. A firm understanding of the detailed chemical and structural factors that govern catalytic activity is a prerequisite to rational catalyst design.

Innovation: Computational catalyst design. Computational quantum chemistry is a powerful technique that provides detailed, molecular insight that is complementary to traditional laboratory experiments. Using state-of-the-art quantum chemical methods, it is possible to calculate the structures and energies of molecules from first principles with high accuracy. These calculations can be used to elucidate the detailed mechanisms of chemical reactions and to design improved catalysts by identifying chemical factors that 
directly affect the rate-determining step(s) and therefore the product yield and distribution. Modifications of the native reactivity, selectivity, or both, can be explored computationally to design optimized catalysts. For complex molecular systems, hundreds or even thousands of individual quantum chemical calculations are required, necessitating the use of high-performance computing (HPC) resources. Here, we leveraged ORNL high-performance computing expertise and resources to investigate the mechanisms of cobalt-salen catalysts for mild and efficient oxidative delignification of lignin model compounds.

In this project, the Participant (APPTI) and Contractor (ORNL) sought to integrate HPC with conventional experimental approaches to evaluate and optimize cobalt-based delignification catalysts. In addition, the Contractor and Participant collaborated with scientists at the US Forest Service (at no cost) and the University of Tennessee (through a subcontract).

The Contractor and Participant participated in multiple conference calls and met together in person on three occasions during the project (twice in Knoxville, TN and once in Madison, WI).

\section{Benefits to the Funding DOE Office's Mission}

The mission of the DOE Office of Science is to deliver the scientific discoveries and major scientific tools that transform our understanding of nature and advance the energy, economic, and national security of the United States. The work performed in this CRADA specifically benefits the DOE mission in renewable energy, high-performance computing, and energy efficiency in manufacturing.

\section{Technical Discussion of Work Performed by All Parties}

Cobalt salen catalysts activate ambient oxygen to form a cobalt-superoxide radical, a potent electrophile that initiates and terminates radical reactions to degrade lignin. These catalysts can convert lignin-like phenols to benzoquinones or benzaldehydes, both of which are valuable feedstocks. Unfortunately, the catalytic yield is less than desired, and it is unclear how best to modify the catalyst to obtain improved yields. Computational investigation of chemical reaction mechanisms can be used to identify catalytic 'bottlenecks', which is a step toward developing improved catalysts.

In this project, the Contractor performed on the order of one thousand individual quantum chemical calculations on high-performance computational resources at ORNL to generate detailed, accurate reaction pathways for the conversion of lignin-like phenols to benzoquinones and benzaldehydes.

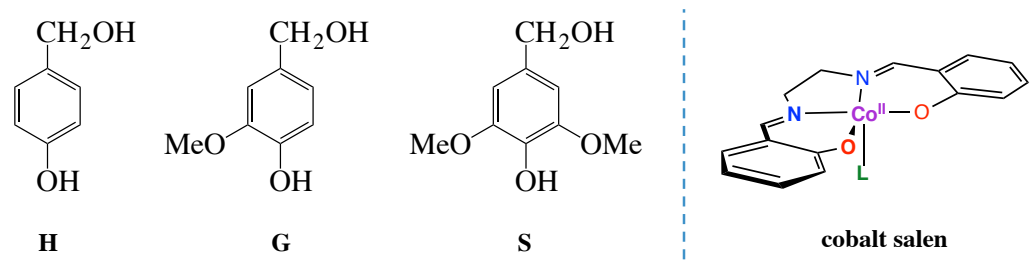

Figure 1. Left: Lignin-like phenols: $\mathrm{H}=4$-hydroxybenzyl alcohol; $\mathrm{G}=$ vanillyl alcohol; $\mathrm{S}=$ syringyl alcohol. Right: cobalt salen catalyst.

Specifically, quantum chemical calculations were performed to determine molecular structures and corresponding free energies for the conversion of 4-hydroxyphenol $(\mathrm{H})$, vanillyl alcohol $(\mathrm{G})$, and syringyl alcohol (S) to the corresponding benzaldehydes and benzoquinones by a cobalt-salen catalyst (Figure 1). Density functional theory (DFT) was used in combination with a polarizable continuum solvent model to perform all the reaction pathway calculations, the results of which are summarized below. 


\section{Computational Methods}

All calculations were performed using a previously described quantum chemical method that was shown to provide an accurate description of a Co(salophen) catalyst system (C. Anson et al., JACS, 2016), which is very similar to the $\mathrm{Co}$ (salen) system investigated here. Briefly, we used the M06-L (Y. Zhao, J. Chem. Phys. 2006) density functional approximation with the LANL2DZ effective core potential and basis set for Co (P.J. Hay, J. Chem. Phys. 1985), the 6-31G(d,p) basis set with 5D functions for all other elements, and the SMD polarizable solvent model (A. Marenich, J. Phys. Chem. B., 2009) with methanol as the solvent. For ${ }^{3} \mathrm{O}_{2}$ only, the gas-phase free energy was used. A standard state correction was added to the gas-phase value to account for a change in concentration of $1 \mathrm{~atm}$ to $1 \mathrm{M}$, i.e. $\Delta \mathrm{G}^{\mathrm{o} \rightarrow *}=\mathrm{RT} \ln (24.5)=$ $1.89 \mathrm{kcal} / \mathrm{mol}$. Vibrational frequencies were calculated to confirm the absence of imaginary frequencies for each minimum-energy state and the presence of a single imaginary frequency corresponding to the reaction of interest for each transition state. All calculations were performed with Gaussian 16 rev A.03 (Frisch, 2016). To generate the reaction free energy diagrams, various species were added as needed to maintain the correct stoichiometry at each step.

\section{Results}

Lignin model oxidations. We performed a designed set of oxidation experiments to examine the mechanism of Co(salen)-catalyzed oxidation of three lignin models, 3,5-dimethoxy-4-hydroxybenzyl alcohol (syringyl alcohol), 3-methoxy-4-hydroxybenzyl alcohol (vanillyl alcohol), and 4-hydroxybenzyl alcohol, which represent the $\mathrm{S}, \mathrm{G}$ and $\mathrm{H}$ substructures present in different forms of lignin ( $\mathrm{S}=$ hardwoods; $\mathrm{G}=$ softwoods; $\mathrm{H}=$ grasses).

Table 1. Formation of benzoquinones from S, G and $\mathrm{H}$ lignin models in the presence of Co(salen).

\begin{tabular}{|l|l|l|}
\hline \\
\hline
\end{tabular}

\footnotetext{
${ }^{a}$ Reaction conditions: $\mathrm{Co}\left(\right.$ salen), $\mathrm{O}_{2}$, base,lignin model, RT, 60 psi.
} 
Quinone formation. Syringyl alcohol was converted to dimethoxybenzoquinone (DMBQ) in 99\% yield after one hour of oxidation when treated with $10 \% \mathrm{Co}$ (salen) in methanol in the presence of pyridine under 60 psi of $\mathrm{O}_{2}$ (Table 1). In contrast, we observed no formation of the (substituted) benzoquinone product when vanillyl alcohol or 4-hydroxybenzyl alcohol were subjected to the same reaction conditions, or alternatively, at an extended reaction time of $22 \mathrm{~h}$.<smiles>[R]c1cc(CO)cc([R2])c1O</smiles>

Role of the axial ligand. To investigate the role of the axial ligand to Co(salen), we carried out additional oxidation reactions of syringyl alcohol without any added base and also in the presence of 2,6-lutidine. In the absence of a base, the yield of DMBQ was $35 \%$ after $1 \mathrm{~h}$ of reaction and also at $22 \mathrm{~h}$ (Table 1). In this case, we hypothesize that the $\mathrm{MeOH}$ solvent serves as a weak axial ligand to $\mathrm{Co}$. When lutidine was used, the yield of DMBQ improved to $48 \%$ after $1 \mathrm{~h}$. This result is consistent with a steric effect, in which the approach of the base to Co is hindered by the presence of the methyl groups flanking the pyridine nitrogen. However, the hindered base may play an additional role in the reaction because the yield with 2,6-lutidine is intermediate between those obtained with no base and with pyridine.

Table 2. Formation of MBQ from a $G$ lignin model in the presence of a bulky, non-coordinating base ${ }^{\mathrm{a}}$

\begin{tabular}{|c|c|c|}
\hline Base & $\mathrm{pK}_{\mathrm{BH}}{ }^{+}$ & Yield of MBQ (\%) \\
\hline
\end{tabular}

${ }^{a}$ Reaction conditions: $\mathrm{Co}\left(\right.$ salen), $\mathrm{O}_{2}$, base, vanillyl alcohol, 60 psi.

Non-coordinating bases. We then examined the addition of bulky, non-coordinating bases to the reaction mixture as a means to promote oxidation of the unreactive lignin models. Using vanillyl alcohol, a series of bases was added to the oxidation reaction (Table 2). In contrast to the complete lack of quinone product when pyridine was used, we observed a substantial yield of the MMBQ in the presence of most bases. The most effective base was DIPEA, which afforded a $68 \%$ yield of MMBQ. Other bases gave lower yields of quinone. Analogous reactions were also carried out using $p$-hydroxybenzyl alcohol, but no oxidation was observed for this substrate. 
We sought to identify a correlation between $\mathrm{p} K_{\mathrm{b}}$ of the base and the quinone yield but, surprisingly, bases with both low and high $\mathrm{p} K_{\mathrm{b}} \mathrm{s}$ (e.g., DIPEA and $\mathrm{DBN}$ ) gave similar quinone yields. A lower bound on $\mathrm{p} K_{\mathrm{b}}$ might exist for these reactions, as $\mathrm{DABCO}\left(\mathrm{p} K_{\mathrm{b}}=8.4\right)$ failed to induce oxidation.

Table 3. Oxidation products of $\mathrm{S}$ lignin models in the presence of $\mathrm{Co}(\mathrm{salen})$.

\begin{tabular}{|c|c|c|c|c|}
\hline Substrate & $\begin{array}{c}\text { Base } \\
\text { added }\end{array}$ & $\begin{array}{c}\text { Reaction } \\
\text { time }(\mathrm{h})\end{array}$ & \multicolumn{2}{|c|}{ Yield \% } \\
\cline { 3 - 5 } & & 1 & 52 & 26 \\
\hline
\end{tabular}

${ }^{a}$ Reaction conditions: Co(salen), $\mathrm{O}_{2}$, syringyl alcohol in methanol, RT, 60 psi.

Aldehyde formation. Oxidation of lignin models can also result in the formation of benzaldehydes in the absence of a coordinating base. We observed that reactions carried out for shorter times (i.e., $1 \mathrm{~h}$ ) generated higher yields of aldehyde compared to longer reaction times (Table 3). In the presence of 2,6lutidine, oxidation of syringyl alcohol for $1 \mathrm{~h}$ gave 26\% aldehyde and 52\% DMBQ. Extending the reaction time to 22 hours led to a slightly lower aldehyde yield (15\%) and a minor increase in the yield of DMBQ (58\%). Similar results were obtained in the absence of lutidine, which afforded an aldehyde yield of $23 \%$ and DMBQ yield of $36 \%$ after $1 \mathrm{~h}$. After $22 \mathrm{~h}$, the yield of aldehyde dropped to $8 \%$, while that of DMBQ increased only slightly to $41 \%$. Thus, it is possible that aldehydes may serve as intermediates for quinone formation.<smiles>[R]c1cc(C=O)cc([R])c1O</smiles>

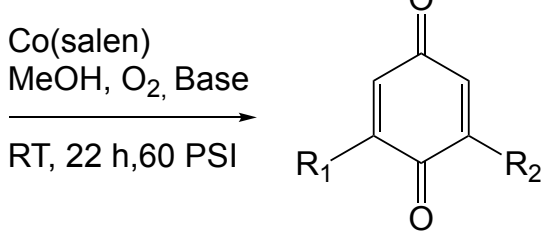

$H: R_{1}, R_{2}=H$

G: $\mathrm{R}_{1}=\mathrm{H}, \mathrm{R}_{2}=\mathrm{OMe}$

S: $R_{1}, R_{2}=O M e$

Aldehydes as intermediates in quinone formation. We examined the possibility that aldehydes serve as a source of quinones by carrying out oxidations of three lignin model aldehydes under different conditions. In the absence of a coordinating base, syringaldehyde was converted to DMBQ with a yield of $26 \%$ after $1 \mathrm{~h}$ and $94 \%$ after $22 \mathrm{~h}$ (Table 4). However, neither 4-hydroxy-3-methoxybenzaldehyde (vanillin) nor 4hydroxybenzaldehyde was converted to the corresponding quinone under any of the conditions tested (not shown).

Table 4. Formation of DMBQ from syringaldehyde ${ }^{a}$

\begin{tabular}{|l|l|l|l|} 
Substrate & Base added & Reaction time (h) & Yield \% \\
\hline
\end{tabular}




\begin{tabular}{|c|c|c|c|}
\hline Co(salen) & 1 & 3.2 \\
\hline Co(salen) & \\
\hline Co(salen) & & 1 & 26 \\
\hline & & 1 & 0 \\
\hline
\end{tabular}

${ }^{a}$ Reaction conditions: $\mathrm{Co}\left(\right.$ salen), $\mathrm{O}_{2}$, syringyl alcohol in methanol, RT, 60 psi.

Small amounts of aldehydes were generally observed in successful oxidations. Thus, we tested the oxidation of 3,4,5-trimethoxybenzyl alcohol to assess the formation of aldehydes through the removal of a benzylic hydrogen in a system lacking a phenolic hydrogen (Table 5). Under standard oxidation conditions, the yield of aldehyde remained low $(<10 \%)$. However, when the organic base was replaced with $\mathrm{NaOH}$, oxidation occurred over longer reaction times $(80 \mathrm{~h}$ ). The primary oxidation product in this case was not the aldehyde, but the corresponding carboxylic acid. Under these conditions, the aldehyde, which will show higher reactivity than the starting alcohol, undergoes further reaction to form the acid.

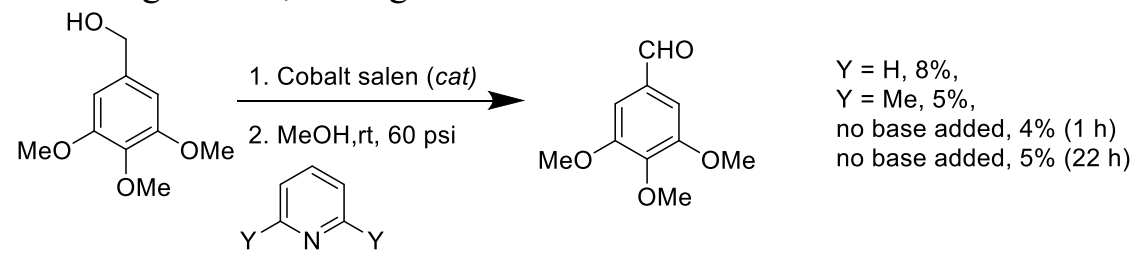

Table 5. Formation of benzaldehyde from 3,4,5-trimethoxybenzyl alcohol

\begin{tabular}{|l|l|l|l|}
\hline Catalyst added & Base added & Reaction time (h) & Yield (\%) \\
\hline Co(salen) & pyridine & 1 & 8 \\
\cline { 3 - 4 } & & 22 & 8.5 \\
\hline $\mathrm{Co}($ salen$)$ & lutidine & 1 & 5 \\
\hline $\mathrm{Co}($ salen$)$ & & 1 & 4 \\
\cline { 3 - 4 } & & 22 & 5 \\
\cline { 3 - 4 } & & 22 & 6 \\
\hline $\mathrm{Co}($ salen $)$ & $\mathrm{NaOH}$ & 22 & 2 \\
& & $22(80)$ & 87 (carboxylic acid) \\
\hline
\end{tabular}

\section{Computational analysis}

To provide additional insight into the mechanisms of lignin oxidation by the $\mathrm{Co}$ (salen) catalyst, we used DFT to calculate reaction pathways for the formation of quinones and aldehydes from the corresponding S, $\mathrm{G}$, and $\mathrm{H}$ lignin models. We generated complete reaction pathways, including catalyst reactivation steps, both with and without a pyridine ligand.

\section{Catalyst reactivation}


Previously proposed mechanisms for the oxidation of phenols by Co-Schiff base catalysts have included the formation of $\mathrm{Co}^{\mathrm{III}}$-hydroxide and $\mathrm{Co}^{\mathrm{III}}$-hydroperoxide complexes (D. Cedeno et al., Tet. Lett. 2012). However, a detailed mechanistic investigation of the reactivation of these species in the context of lignin model oxidation is lacking.

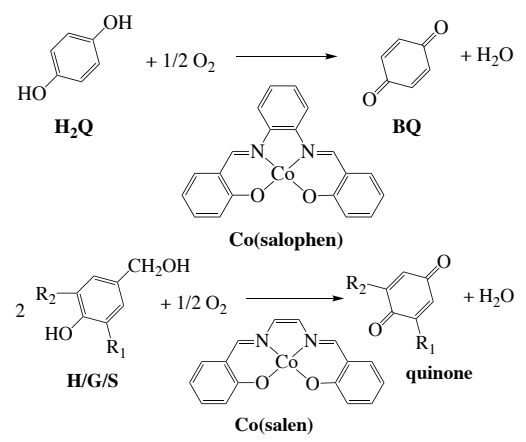

Recently, a mechanism was proposed for the aerobic oxidation of $p$-hydroquinone to form benzoquinone catalyzed by a closely related Co ${ }^{\mathrm{II}}$ (salophen) catalyst (C. Anson et al., JACS, 2016). In that pathway, two equivalents of $p$-hydroquinone are converted to two equivalents of benzoquinone per equivalent of $\mathrm{O}_{2}$, i.e. both phenolic $\mathrm{OH}$ groups of $p$-hydroquinone undergo oxidation (Figure 1). However, in the present case each lignin model contains only a single phenolic group, so catalyst reactivation is expected to require four equivalents of a given lignin model per molecule of $\mathrm{O}_{2}$. For our purposes, that study is important for two reasons: First, it provides a thoroughly validated DFT-based approach for describing oxidation reactions catalyzed by a Co-Schiff base catalyst. In addition, it provides an informative starting point for identifying plausible catalyst reactivation pathways involving lignin models.

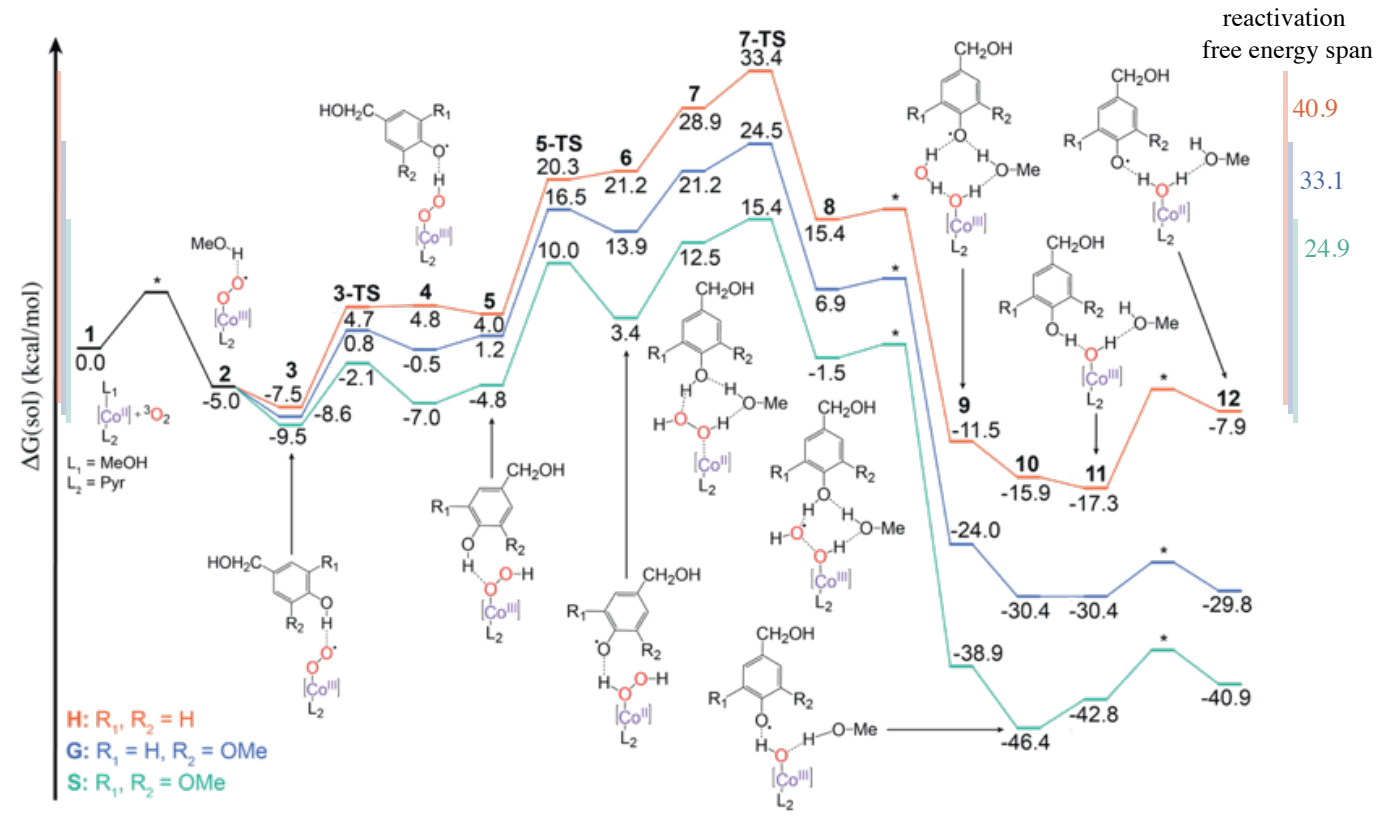

Figure 2. Free energy diagram for the initial formation of the active $\mathrm{Co}^{\mathrm{III}}$-superoxo catalyst with an axial pyridine ligand and subsequent catalyst regeneration during oxidation of $\mathrm{S}, \mathrm{G}$, and $\mathrm{H}$ lignin models. Phenolic radicals generated at 4, 6, 9 and 12 can feed into the quinone and aldehyde pathways.

Oxidation of the lignin models begins with binding of $\mathrm{O}_{2}$ to $\mathrm{Co}^{\mathrm{II}}$ (salen) to form $\mathrm{Co}^{\mathrm{III}}$-superoxo adduct 2 (Figure 1). This step was calculated to be energetically downhill by $5.0 \mathrm{kcal} / \mathrm{mol}$. Association of each lignin model to form intermediate $\mathbf{3}$ is further energetically downhill and follows the pattern that $\mathbf{3}$ is most favorable for the $\mathrm{S}$ model $(-9.5 \mathrm{kcal} / \mathrm{mol})$, followed by the $\mathrm{G}$ model $(-8.6 \mathrm{kcal} / \mathrm{mol})$ and finally, the least 
favorable $\mathrm{H}$ model $(-7.5 \mathrm{kcal} / \mathrm{mol})$. Abstraction of the phenolic hydrogen from each lignin model by the

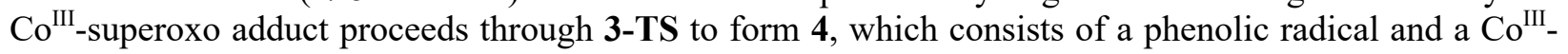
hydroperoxo complex. The phenolic radicals can then enter either the benzoquinone or benzaldehyde pathway (see below).

Catalyst reactivation pathway begins after the formation of $\mathrm{Co}^{\mathrm{III}}$-hydroperoxo species 4 , in which the nascent phenolic radical departs and is replaced by a second equivalent of the $\mathrm{S}, \mathrm{G}$, or $\mathrm{H}$ lignin model to form 5 (Figure 1). The phenolic hydrogen is then abstracted by the proximal oxygen of the $\mathrm{Co}^{\mathrm{III}}$ hydroperoxo species through a proton-coupled electron transfer step, resulting in the formation of Co (salen) with a loosely coordinated $\mathrm{H}_{2} \mathrm{O}_{2}$ axial ligand, 6, via 5-TS. Replacement of the resulting phenolic radical with another equivalent of phenol, along with incorporation of methanol into a hydrogen bond network, generates intermediate 7. $\mathrm{H}_{2} \mathrm{O}_{2}$ then undergoes homolysis through 7-TS to generate a hydroxyl radical and a $\mathrm{Co}^{\mathrm{III}}$-hydroxo species in $\mathbf{8}$. The phenolic hydrogen from a third equivalent of $\mathrm{S} / \mathrm{G} / \mathrm{H}$ is transferred to the hydroxyl radical to form $\mathrm{H}_{2} \mathrm{O}$ and another phenolic radical in $\mathbf{9}$. The phenolic radicals generated throughout the reactivation pathway $(4,6,9$, and 12 in Figure 1) can feed back asynchronously into the quinone and aldehyde pathway discussed below. All steps from $\mathbf{9}$ onward are lower in free energy than the reactants, indicating their favorability.

The calculations indicate that transition state 7-TS is the highest-energy state of the reactivation pathway for all three lignin models. The highest-energy state for reactivation with the $\mathrm{S}$ model is the lowest (24.9 $\mathrm{kcal} / \mathrm{mol})$, the reaction for the $\mathrm{G}$ model is less favorable $(33.1 \mathrm{kcal} / \mathrm{mol})$, and the $\mathrm{H}$ model is the least favorable $(40.9 \mathrm{kcal} / \mathrm{mol})$. Thus, the $\mathrm{G}$ and $\mathrm{H}$ pathways are 8.2 and $16.0 \mathrm{kcal} / \mathrm{mol}$ higher in energy than the $\mathrm{S}$ model, respectively).

We also calculated free energy diagrams for the analogous catalyst reactivation pathways without a pyridine ligand to Co. The highest-energy state for reactivation with the $\mathrm{S}$ model is the lowest $(21.9 \mathrm{kcal} / \mathrm{mol})$, followed by the $\mathrm{G}$ model $(31.4 \mathrm{kcal} / \mathrm{mol})$, and the $\mathrm{H}$ model $(37.5 \mathrm{kcal} / \mathrm{mol})$ (not shown). In energetic terms the most stable intermediate in all pathways for all three lignin models is $\mathbf{3}$, which sets the energetic baseline for determining the activation barrier for each reaction. Although the highest-energy states (7-TS) for catalyst reactivation are slightly lower in free energy in the presence of pyridine, the overall barriers are higher because pyridine coordination lowers the energy of $\mathbf{3}$. 


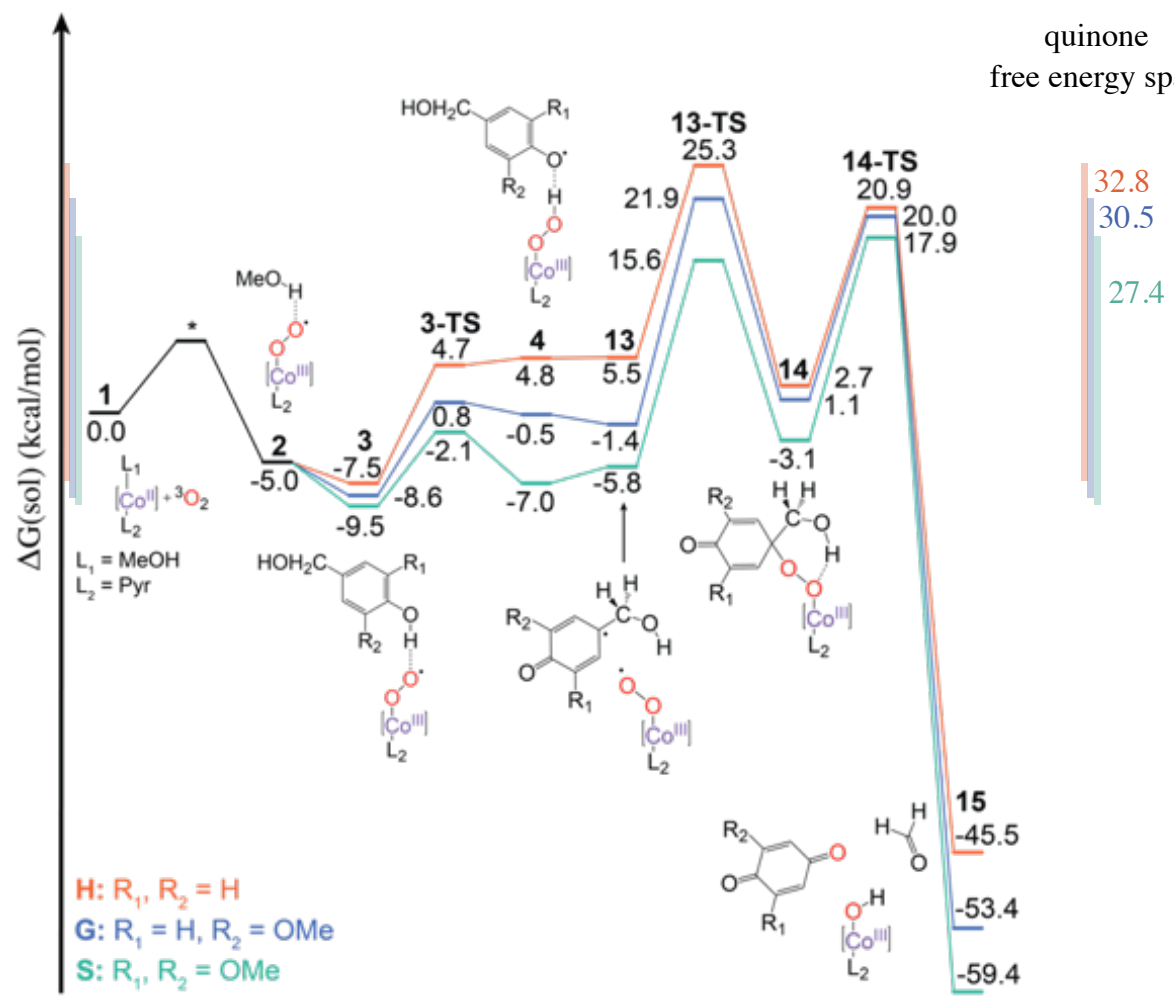

Figure 2. Free energy profile for the catalytic oxidation of lignin model compounds by Co(salen) with an axial pyridine ligand to form benzoquinones.

Benzoquinone formation. For the catalytic cycle to continue, the $\mathrm{Co}^{\mathrm{III}}$-hydroperoxo species must be converted back to the $\mathrm{Co}^{\mathrm{III}}$-superoxo state, or it must be displaced by a second equivalent of the $\mathrm{Co}^{\text {III- }}$ superoxo adduct. At early stages of the reaction, we expect that the $\mathrm{Co}^{\mathrm{III}}$-superoxo adduct will be present in abundance because its formation from $\mathrm{Co}^{\mathrm{II}}$ (salen) and $\mathrm{O}_{2}$ is energetically favorable. Thus, we assume a $\mathrm{Co}^{\mathrm{III}}$-superoxo species is available to enable formation of $\mathbf{1 3}$.

Radical coupling with a phenolic radical then proceeds through 13-TS to form covalent complex 14 (Figure 2). This complex then decomposes via 14-TS to produce formaldehyde, a catalytically inactive Co ${ }^{\text {III }}$ hydroxo complex, and the benzoquinone product. Either 13-TS or 14-TS is rate-limiting, depending on the substrate and the presence/absence of a pyridine ligand. Whereas for $\mathrm{S}$ the highest-energy state is 14-TS in both systems, 13-TS is slightly higher $(1.9 \mathrm{kcal} / \mathrm{mol})$ in free energy than 14-TS for the G model in the pyridine complex and substantially lower $(4.3 \mathrm{kcal} / \mathrm{mol})$ when pyridine is absent. In the quinone pathway without pyridine, the formation of the $\mathrm{Co}^{\mathrm{III}}$-superoxo species is $3.5-4.7 \mathrm{kcal} / \mathrm{mol}$ less favorable than when pyridine is included (Figure S2). Thus, as with reactivation the overall barriers in the presence of pyridine are higher because pyridine coordination lowers the energy of $\mathbf{3}$.

The pathway leading to benzoquinone formation results in the formation of both a $\mathrm{Co}^{\mathrm{III}}$-hydroperoxo and $\mathrm{Co}^{\mathrm{III}}$-hydroxo species (Figure 2). The inactive $\mathrm{Co}^{\mathrm{III}}$-hydroxo complex in $\mathbf{1 5}$ can be easily reactivated by bypassing 7-TS and entering the reactivation pathway at any point between 9 and $\mathbf{1 1}$ (Figure 1).

However, the $\mathrm{Co}^{\mathrm{III}}$-hydroperoxo complex must proceed from $\mathbf{4}$ to $\mathbf{5}$ in the reactivation pathway, passing through the energetically unfavorable 7-TS. From 12, departure of $\mathrm{H}_{2} \mathrm{O}$ and methanol and binding of $\mathrm{O}_{2}$ to $\mathrm{Co}^{\mathrm{II}}$ (salen) results in $\mathbf{1 3}$.

Taken together, the energetics of benzoquinone formation and catalyst reactivation explain the experimentally observed quinone yields for the three substrates. Under the reaction conditions tested, the 
$\mathrm{H}$ lignin model did not undergo oxidation to form benzoquinone. The calculated free energy barrier for quinone formation with pyridine is $32.8 \mathrm{kcal} / \mathrm{mol}$ (Figure 2), but the barrier for catalyst reactivation is $40.9 \mathrm{kcal} / \mathrm{mol}$ (Figure 1). Thus, the inability of the $\mathrm{H}$ model to facilitate catalyst reactivation prevents oxidation, consistent with the experimental observations (Table 1). In contrast, the calculated free energy barrier for DMBQ formation from syringyl alcohol is $27.4 \mathrm{kcal} / \mathrm{mol}$ with pyridine and the reactivation barrier is $24.9 \mathrm{kcal} / \mathrm{mol}$. Thus, the much lower overall free energy barrier for oxidation of the $\mathrm{S}$ model is consistent with the nearly quantitative conversion to DMBQ observed experimentally (Table 1).

For the $\mathrm{G}$ model, the calculated free energy barrier for MBQ formation $(30.5 \mathrm{kcal} / \mathrm{mol})$ and catalyst reactivation $(33.1 \mathrm{kcal} / \mathrm{mol})$ are intermediate between those of the $\mathrm{H}$ and $\mathrm{S}$ models. No quinone production was observed experimentally for this substrate when pyridine was present (Table 1). However, the use of bulky, non-coordinating bases resulted in yields of up to $68 \%$ (Table 2). Thus, it is possible that the base could deprotonate the benzylic oxygen of the substrate, which could potentially lower the energy of 13-TS, 14-TS, or both. We do not expect that a base would lower the free energy barrier for catalyst reactivation, i.e. 7-TS.

\section{Aldehyde formation}

The calculated pathway for the oxidation of the lignin models to form benzaldehydes begins in the same

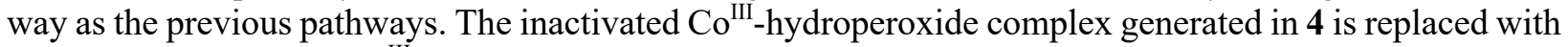
a second equivalent of $\mathrm{Co}^{\mathrm{III}}$-superoxo adduct to form 16. Transfer of a benzylic hydrogen from the phenol radical in 16 via 16-TS results in the formation of 17, which consists of a quinone methide and $\mathrm{Co}^{\mathrm{III}}$ hydroperoxide. Thus, the $\mathrm{Co}^{\mathrm{III}}$-hydroperoxo complex is produced at two points in the aldehyde pathway, both of which must go through the energetically unfavorable 7-TS. The quinone methide then undergoes tautomerization to form the benzaldehyde product.

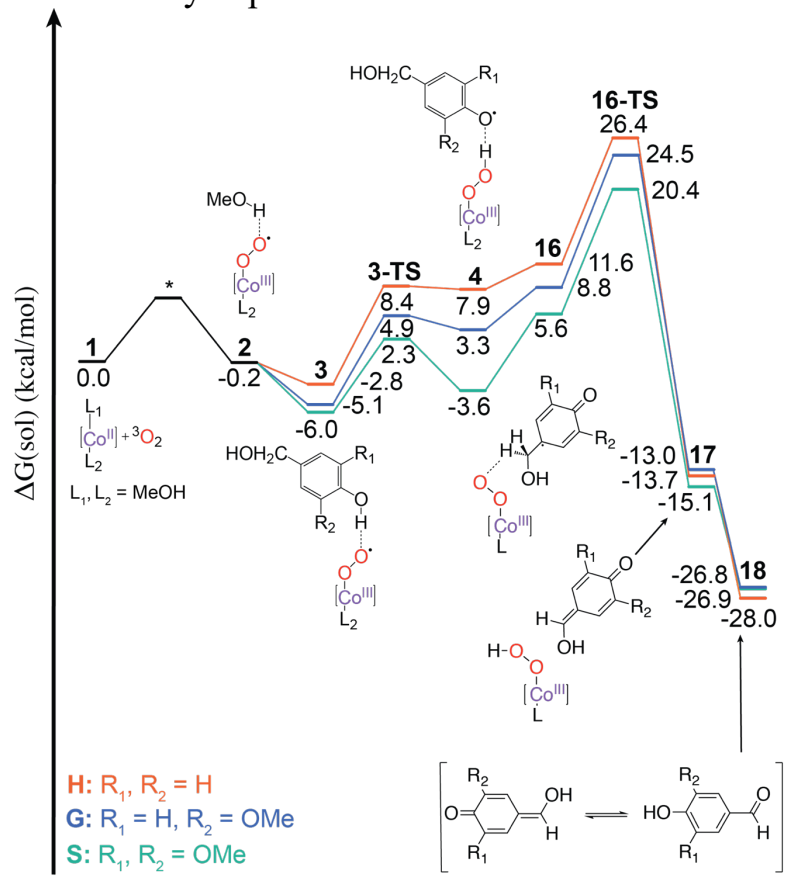

Figure 3. Free energy profile for the catalytic oxidation of lignin model compounds by Co(salen) without an axial pyridine ligand to form benzaldehydes.

Experimentally, no aldehyde production was observed for the $\mathrm{S}$ lignin model when a pyridine ligand was present. However, with pyridine-free catalyst the S lignin model gave a yield of 36\% DMBQ and 23\% syringaldehyde after $1 \mathrm{~h}$ (Table 3). Thus, the overall free energy barrier for DMBQ formation should be slightly lower than that for syringaldehyde. 
Exchange of the $\mathrm{Co}^{\mathrm{III}}$-hydroperoxo complex in $\mathbf{4}$ with $\mathrm{Co}^{\mathrm{III}}$-superoxo adduct to form $\mathbf{1 6}$ is uphill energetically, with $\Delta \mathrm{G}=8.0,5.5$, and $3.7 \mathrm{kcal} / \mathrm{mol}$ for the $\mathrm{S}, \mathrm{G}$, and $\mathrm{H}$ models, respectively (Figure 3). For 16-TS the activation barriers follow the trend: $\mathrm{G} \approx \mathrm{H}>\mathrm{S}$, with free energies of $29.6,29.2$, and $26.4 \mathrm{kcal} / \mathrm{mol}$, respectively, relative to $\mathbf{3}$. From $\mathbf{1 7}$ to $\mathbf{1 8}$, the free energy difference is $11.8 \mathrm{kcal} / \mathrm{mol}$ for, indicating a thermodynamic driving force for syringaldehyde formation from the corresponding quinone methide intermediate.

We next compared the energetics of quinone and aldehyde formation in the absence of pyridine (data not shown). The computed free energy barriers relative to 3 for the formation of DMBQ are $30.0 \mathrm{kcal} / \mathrm{mol}$ and 26.4 (Figure 3) for syringaldehyde. The corresponding reactivation barrier is $21.9 \mathrm{kcal} / \mathrm{mol}$ and therefore should not be a factor in determining the overall reactivity.

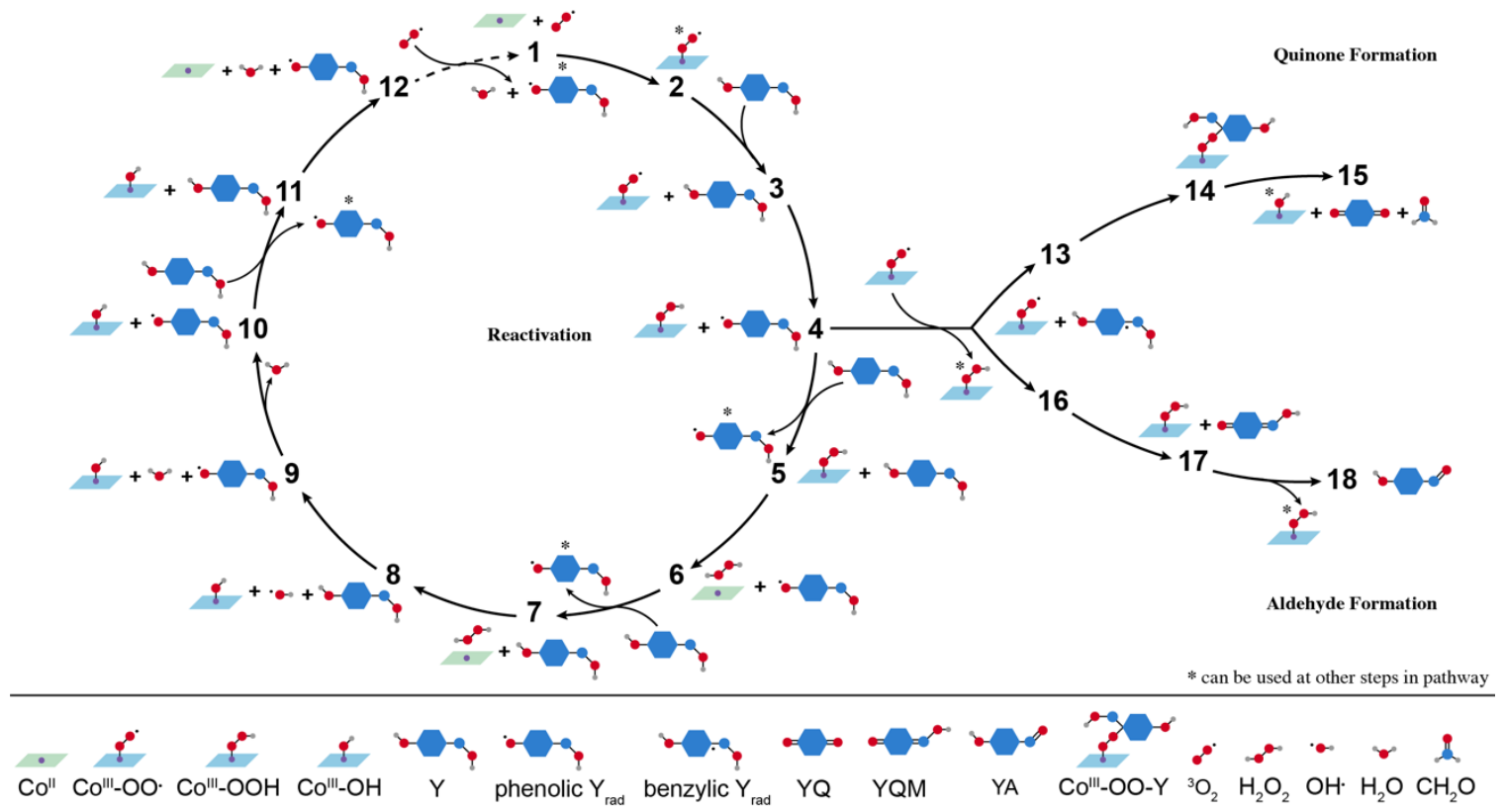

Figure 4. Proposed mechanism for the formation of benzoquinones and benzaldehydes from lignin models. The lower-axial ligand to Co was omitted for simplicity.

The reaction mechanisms for the formation of quinones and aldehydes are consistent with previously proposed mechanisms and provide substantial new insight into the determinants of catalytic efficiency (or lack thereof). The high free energy barrier for replenishing the active catalyst from the inactivated Cohydroperoxo complex effectively blocks the formation of methoxybenzoquinone and benzoquinone from the $\mathrm{G}$ and $\mathrm{H}$ lignin models, respectively. The presence of a pyridine ligand to Co increases the barrier for reactivation for $\mathrm{H}, \mathrm{G}$ and $\mathrm{S}$ by generating an energetically lower-lying intermediate than in the corresponding pyridine-free case. Whereas the quinone pathway generates a single $\mathrm{Co}^{\mathrm{III}}$-hydroperoxide that must be reactivated to sustain full catalytic activity, the aldehyde pathway generates two equivalents of this intermediate per turnover. Thus, aldehyde formation may be more limited by reactivation bottlenecks than quinone formation.

Major findings of the work were that sustained catalyst reactivation is a critical factor for driving the reaction to completion, and the phenolic substrate plays an autocatalytic role in reactivation. In the laboratory, syringyl alcohol (S) is readily converted to 2,6-dimethoxybenzoquinone (DMBQ), but 4hydroxybenzyl alcohol $(\mathrm{H})$ is completely unreactive. Our calculations showed clearly that the reason for 
the lack of reaction in the case of $\mathrm{H}$ is that this compound cannot facilate conversion of the cobalt salen back to its catalytically active form.

These findings and others will be described in a forthcoming peer-reviewed journal publication.

\section{Subject Inventions (As defined in the CRADA)}

None.

Commercialization Possibilities

None.

\section{Plans for Future Collaboration}

The Contractor is interested in pursuing follow-on funding to build on the foundation established through this CRADA. Collaborators at the USDA Forest Products Laboratory (FPL) and US Forest Service are particularly interested in continuing work with ORNL. In particular, a major aim is to harness the insights gained in this work to design next-generation cobalt salen catalysts with improved efficiency.

\section{Conclusions}

The Contractor performed extensive computational chemistry calculations and complementary lab experiments to establish a thorough understanding of the chemical mechanism of a cobalt-based delignification catalyst. This insight was intended to guide the rational design of prospective new cobaltbased catalysts that break down lignin more efficiently. The results of this CRADA have provided unprecedented insight into the complex nature of homogeneous transition metal catalysts of great interest to the paper industry.

The overarching goal of this work was to reduce the financial and labor cost of catalyst discovery by using rational, mechanism-based catalyst design and computational screening to evaluate potential leads. It is hoped that our findings will lead to the design of new delignification catalysts that are more efficient and selective for lignin than existing catalysts. 